\title{
Post-mortem imaging in forensic investigations: current utility, limitations, and ongoing developments
}

This article was published in the following Dove Press journal:

Research and Reports in Forensic Medical Science

16 March 2016

Number of times this article has been viewed

\author{
Silke Grabherr' \\ Pia Baumann' \\ Costin Minoiu' ${ }^{1,2}$ \\ Stella Fahrni ${ }^{3}$ \\ Patrice Mangin' \\ 'Department of Forensic Imaging, \\ University Center of Legal Medicine. \\ University of Lausanne, Lausanne, \\ Switzerland; ${ }^{2}$ Department of \\ Radiology, University of Medicine and \\ Pharmacy "Carol Davila", Bucharest, \\ Romania; ${ }^{3}$ School of Criminal Justice \\ and Forensic Science, University of \\ Lausanne, Lausanne, Switzerland
}

Correspondence: Silke Grabherr Department of Forensic Imaging, University Center of Legal Medicine, University of Lausanne, Chemin de la Vuillette 4, I00I Lausanne 25, Switzerland

Tel +4I 2I 2I 7967

Email silke.grabherr@chuv.ch

\begin{abstract}
Forensic imaging is a new field with increasing application all over the world. However, its role in legal medicine is controversial, mostly due to the use of undefined and unclear terms. The aim of this article is to describe forensic imaging and to explain the various techniques that pertain to it. Essentially, these methods consist of radiological methods such as conventional radiography, computed tomography, and magnetic resonance imaging, but other techniques such as 3D surface scanning are also employed. Computed tomography can be combined with minimally invasive strategies such as image-guided sampling or post-mortem angiography. We provide an overview of the advantages and limitations of these methods, which must be identified and understood to enable correct application.
\end{abstract}

Keywords: forensic imaging, post-mortem computed tomography, magnetic resonance imaging, forensic radiology, virtual autopsy

\section{Introduction}

In recent years, modern imaging methods, especially radiological cross-sectional imaging, have found their way into the daily routine of forensic practice in centers all over the world. Due to the increased use of imaging for forensic purposes as well as the establishment of specific research projects, the number of published studies in this field has increased rapidly in recent years. This new domain of research is interesting to radiologists as well as to forensic pathologists; radiologists have been involved in most forensic imaging projects from the beginning, underscoring the field's integration of two distinct medical specialties. While radiologists read the obtained images, forensic pathologists focus on findings important for medico-legal reconstructions, which are not necessarily important from a clinical point of view. Pathologists are also able to explain certain phenomena visible on images due to their knowledge of thanatology.

Although many articles have been published in radiological and forensic journals, in the early years of modern post-mortem imaging, most of these articles consisted of case reports or feasibility studies conducted on a small number of cases. Large, basic scientific studies were unfortunately missing during this early period, which is perhaps why the medico-legal community was remarkably skeptical of new post-mortem imaging methods. There was much speculation about the role of these methods and their relationship to forensic autopsy. Unclear study designs and unscientific terms were often used, leading to unsupported conclusions that were questioned. Confusion was further increased by the use of undefined or unclear terms such as "necroradiology", "forensic radiology", "virtual autopsy", and "minimally invasive autopsy", which were 
rarely explained in the articles. In particular, the term "virtual autopsy" aroused extensive discussion, as it suggests that this kind of "autopsy" replaces the conventional "real autopsy". These issues created conflict regarding the implementation of two completely different procedures, resulting in distinct opinions on the use of imaging methods in legal medicine.

The aim of this review is to define the core concept of forensic imaging. We also present relevant technologies and their respective pros and cons, thus establishing the role of modern imaging in the field of forensic medicine.

\section{Current methods of post-mortem forensic imaging}

All of the radiological techniques currently used in legal medicine are derived from clinical practice and employ available imaging modalities. Other imaging methods can also be implemented; for example, 3D surface scanning is a technology that was adapted from the car industry. Although photography is also a part of forensic imaging, in this review, we will focus on the techniques most often categorized as forensic imaging: conventional radiography, post-mortem computed tomography (PMCT) and the minimally invasive approaches associated with it, magnetic resonance imaging (MRI), and 3D surface scanning. An overview of these methods and their respective advantages and disadvantages appear in Table 1.

\section{Conventional radiography}

Conventional radiography is the oldest radiological imaging method used in forensic medicine. In this technique, the body is investigated via direct exposure to X-rays; structures exposed to the beam are projected onto a radiographic image. The image is composed of different tonalities of black and white, corresponding to the number of X-rays that reach the detector. Contrast is possible due to the distinct absorption properties of body structures (bone is associated with high absorption and soft tissues display less attenuation). Conventional radiography employs two types of devices available in medical institutions: 1) analog equipment that uses radiological film for the impression of images, and 2) newer equipment that is completely digitized. In digital and digitized analog equipment, images are acquired in digital DICOM format, which is currently used for all imaging modalities.

Immediately after their discovery by Wilhelm Conrad Röntgen in 1895, X-rays were employed in post-mortem investigations, ${ }^{1}$ especially in anthropology. For example, there are records of the radiography of a mummified hand of an Egyptian princess in $1896 .^{2}$ This example indicates that the complementarity of forensic medicine and X-ray-based techniques was recognized from the beginning.

One of the most famous cases that employed conventional radiography occurred in 1935 in Scotland. ${ }^{3}$ Human body parts were discovered in a river and subsequently identified as belonging to two women who were probably dismembered. At the same time, the nurse and the wife of a doctor in Lancaster were reported missing. Radiological examination of the body parts enabled rapid assessment of the age and size of the two victims. Identification was carried out by superposing X-ray images of the skulls with photographs of the alleged victims. The surgical precision used to dismember the two women as well as other information suggested that the perpetrator possessed medical skills. The doctor from Lancaster was ultimately convicted of these crimes.

Conventional radiography is one of the most common imaging modalities in forensic medicine worldwide. Most forensic institutions possess their own X-ray devices, which are often used to evaluate the osseous system in cases of trauma or to characterize the presence of a foreign body. Radiography is advantageous, as it is simple to perform, rapid, and cost-efficient. Radiography is often implemented for infant corpses, for highly putrefied, charred, or otherwise altered bodies, and for bodies of unknown identity. Conventional radiography can also provide important information that is integrated with other complementary exams for age determination (Figure 1), not only of deceased but also of living persons. ${ }^{4-6}$ Nowadays, conventional radiography is often replaced with multi-detector computed tomography (MDCT), which allows 3D representation of any segment of the human body as well as better soft-tissue contrast. However, due to the common availability of conventional radiography and the specific indications that justify its use, such as the examination of corpses and objects that cannot be examined by CT due to a large volume, conventional radiography still plays an important role in legal medicine.

\section{PMCT}

Currently, one of the most-used radiological modalities in modern forensic imaging is MDCT. This extensive use means that the term PMCT often refers to MDCT.

Unlike conventional radiography, MDCT uses a computer to generate images that are saved in DICOM format. MDCT is based on the principle that the density of each tissue can be measured by calculating the attenuation coefficient of an $\mathrm{X}$-ray beam passing through it. The body is examined through direct exposure to $\mathrm{X}$-rays via a rotating tube. The attenuation values of the X-rays are expressed in Hounsfield units; these 
Table I Overview of forensic imaging methods and their advantages, disadvantages, and fields of application

\begin{tabular}{|c|c|c|c|}
\hline Method & Advantages & Disadvantages & Field of application \\
\hline $\begin{array}{l}\text { Conventional } \\
\text { radiography }\end{array}$ & $\begin{array}{l}\text { Fast examination } \\
\text { Easy to handle } \\
\text { Simple data storage } \\
\text { Relatively low maintenance costs } \\
\text { Visualization of the skeletal system } \\
\text { Detection of foreign bodies }\end{array}$ & $\begin{array}{l}\text { Radiation (need for specific protection } \\
\text { for the personnel) } \\
\text { No 3D reconstructions } \\
\text { Very limited visualization of soft tissue } \\
\text { Superimposed image } \\
\text { Quality strongly dependent on } \\
\text { acquisition }\end{array}$ & $\begin{array}{l}\text { Detection of foreign bodies } \\
\text { Identification } \\
\text { Age estimation } \\
\text { Changes/lesions of the skeletal } \\
\text { system }\end{array}$ \\
\hline $\mathrm{PMCT}$ & $\begin{array}{l}\text { Fast examination } \\
\text { Easy to handle } \\
\text { Ideal for 3D reconstructions } \\
\text { Relatively low maintenance costs } \\
\text { Excellent visualization of skeletal } \\
\text { system and gas }\end{array}$ & $\begin{array}{l}\text { Radiation (need for specific protection } \\
\text { for the personnel) } \\
\text { Data storage } \\
\text { Limited visualization of soft tissue, } \\
\text { organs, vascular system } \\
\text { Training needed for correct interpretation }\end{array}$ & $\begin{array}{l}\text { Trauma cases, especially lesions of } \\
\text { the skeletal system (accidents, falls } \\
\text { from heights, traffic accidents, blunt } \\
\text { trauma) } \\
\text { Sharp trauma } \\
\text { Gunshot trauma } \\
\text { Child abuse } \\
\text { Detection of foreign bodies } \\
\text { Identification } \\
\text { Age estimation } \\
\text { Detection of gas embolism } \\
\text { Changes in the skeletal system }\end{array}$ \\
\hline PMCT-angiography & $\begin{array}{l}\text { Minimally invasive } \\
\text { Good visualization of soft tissue and } \\
\text { organs, especially the vascular system } \\
\text { Ideal for 3D reconstruction of the } \\
\text { vascular system } \\
\text { Method of choice to detect lesions } \\
\text { of the vascular system }\end{array}$ & $\begin{array}{l}\text { Relatively time-consuming } \\
\text { Data storage } \\
\text { Special training needed } \\
\text { Costs of material }\end{array}$ & $\begin{array}{l}\text { Trauma cases (accidents, falls from } \\
\text { heights, traffic accidents) } \\
\text { Sharp trauma } \\
\text { Gunshot trauma } \\
\text { Bleeding, vascular lesions } \\
\text { Death after surgical intervention } \\
\text { Pathologies of the coronary arteries } \\
\text { (evaluation of stenosis) and sudden } \\
\text { cardiac death } \\
\text { Detection of malformations of the } \\
\text { vessels }\end{array}$ \\
\hline CT-guided sampling & $\begin{array}{l}\text { Minimally invasive } \\
\text { Low risk of sample contamination } \\
\text { Low risk of artifacts } \\
\text { Easy to handle }\end{array}$ & $\begin{array}{l}\text { Relatively time-consuming } \\
\text { Special training needed } \\
\text { Data storage }\end{array}$ & $\begin{array}{l}\text { Sampling of body fluids and } \\
\text { samples of organs for toxicological, } \\
\text { microbiological, microscopic, and } \\
\text { immunohistochemical examinations } \\
\text { Sampling of gas for analyzing cases of } \\
\text { putrefied corpses, gas intoxication, } \\
\text { gas embolism, etc }\end{array}$ \\
\hline MRI & $\begin{array}{l}\text { Good visualization of soft tissue, } \\
\text { organs, vascular wall } \\
\text { No radiation }\end{array}$ & $\begin{array}{l}\text { Time-consuming } \\
\text { More difficult to handle } \\
\text { High maintenance costs } \\
\text { Need specific architectural construction } \\
\text { 3D reconstructions need special } \\
\text { sequences } \\
\text { Data storage } \\
\text { Training needed for correct } \\
\text { interpretation }\end{array}$ & $\begin{array}{l}\text { Blunt trauma } \\
\text { Sharp trauma } \\
\text { Strangulation } \\
\text { Child abuse } \\
\text { Medical errors, death after surgical } \\
\text { intervention } \\
\text { Detection of foreign bodies } \\
\text { Age estimation } \\
\text { Identification }\end{array}$ \\
\hline 3D surface scanning & $\begin{array}{l}\text { Good visualization of surface } \\
\text { High resolution }(\mathrm{mm}) \\
\text { Perfect for 3D modeling, } \\
\text { reconstructions } \\
\text { Very low maintenance costs } \\
\text { Mobile }\end{array}$ & $\begin{array}{l}\text { Time-consuming } \\
\text { Extensive training for handling necessary } \\
\text { No information about inner findings } \\
\text { Treatment of data needs a specialist }\end{array}$ & $\begin{array}{l}\text { Trauma cases (traffic accidents, blunt } \\
\text { trauma) } \\
\text { Reconstruction of traffic accidents } \\
\text { Comparison between injury and } \\
\text { injury-causing object } \\
\text { Comparison of bite marks and dental } \\
\text { imprint } \\
\text { Digitalization of objects (eg, bones } \\
\text { for anthropological examination) }\end{array}$ \\
\hline
\end{tabular}

Abbreviations: PMCT, post-mortem computed tomography; MRI, magnetic resonance imaging; CT, computed tomography. 


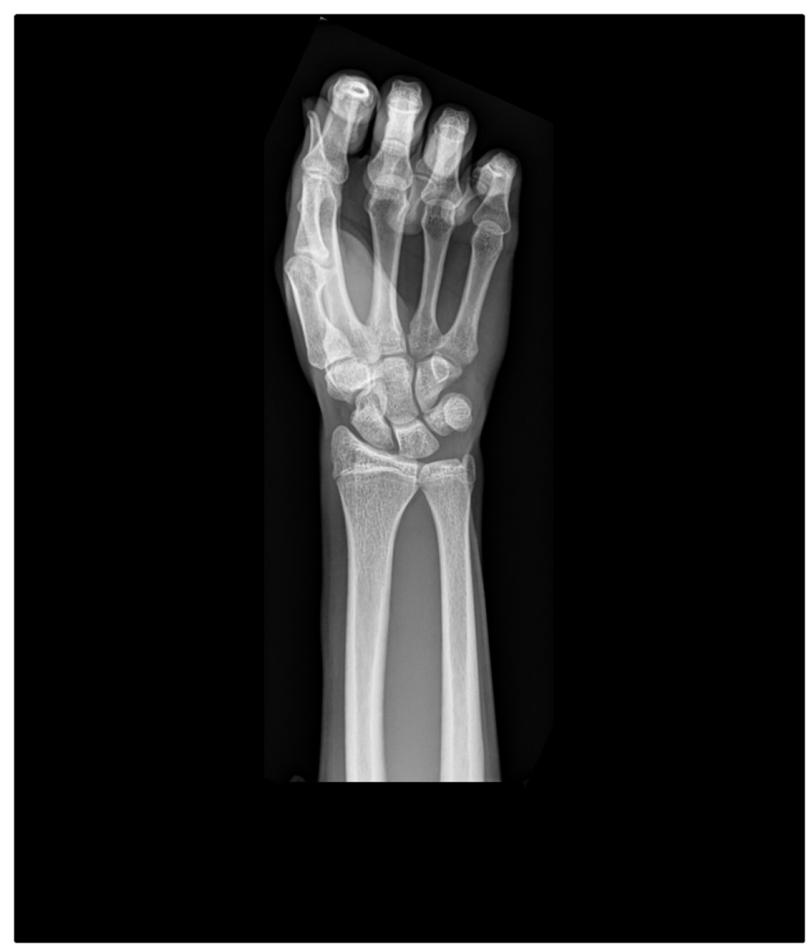

Figure I Conventional radiography of the left wrist and hand of a young, deceased, unknown person.

Note: This image was used for age estimation during identification of the body.

units are characteristic of various tissues and body fluids. Radiographic data are interpreted through the evaluation of various cross-sectional images. While 3D reconstructions are very clear and intuitive, enabling better understanding of the images for a medical layman, radiological assessment and diagnosis should always be based on axial views. Three-dimensional models are always at risk of artifacts, and the assessment of 3D models alone may cause discrete findings to be overlooked. ${ }^{7}$ However, these models are ideal for illustrating findings, for example during meetings with prosecutors or police officers. Additionally, 3D models can be presented in court, as they are less impactful and personal than photos of the deceased.

As MDCT can yield spatial resolution $<1 \mathrm{~mm}$ and offers excellent contrast, particularly for bone, it is the method of choice for assessing the skeletal system ${ }^{8}$ in both clinical and post-mortem imaging. The sensitivity for osseous findings is higher for PMCT than for conventional autopsy, ${ }^{9,10}$ mostly because the determination of many skeletal lesions is only possible through specially adapted dissection methods, including extensive maceration of the soft tissue. PMCT visualizes new and old fractures, even small ones, in poorly accessible skeletal parts such as the posterior parts of the ribs, pelvis, and vertebrae. By using $2 \mathrm{D}$ and especially $3 \mathrm{D}$ reconstruction methods, one can also identify and present complex fractures and the orientation of bone fragments in situ, without the risk of displacing them via direct manipulation (Figure 2).

$\mathrm{CT}$ is the ideal method for detecting radio-opaque foreign bodies. For example, it visualizes medical implants, projectiles and/or their fragments, and swallowed or aspirated foreign bodies. CT makes the discovery of small or fragmented objects much easier than does classic autopsy ${ }^{11-13}$ and allows rapid orientation for targeted extraction during autopsy. However, one of the most significant disadvantages of PMCT versus autopsy is its limited visualization of soft tissue, especially organ parenchyma. Thus, although PMCT is suitable for investigating traumatic ${ }^{9}$ death and hemorrhagic diseases such as cerebral hemorrhage, subarachnoid hemorrhage, aortic dissection, and aortic aneurismal rupture, it may not make a substantial contribution to the determination of non-traumatic death not related to hemorrhagic lesions.

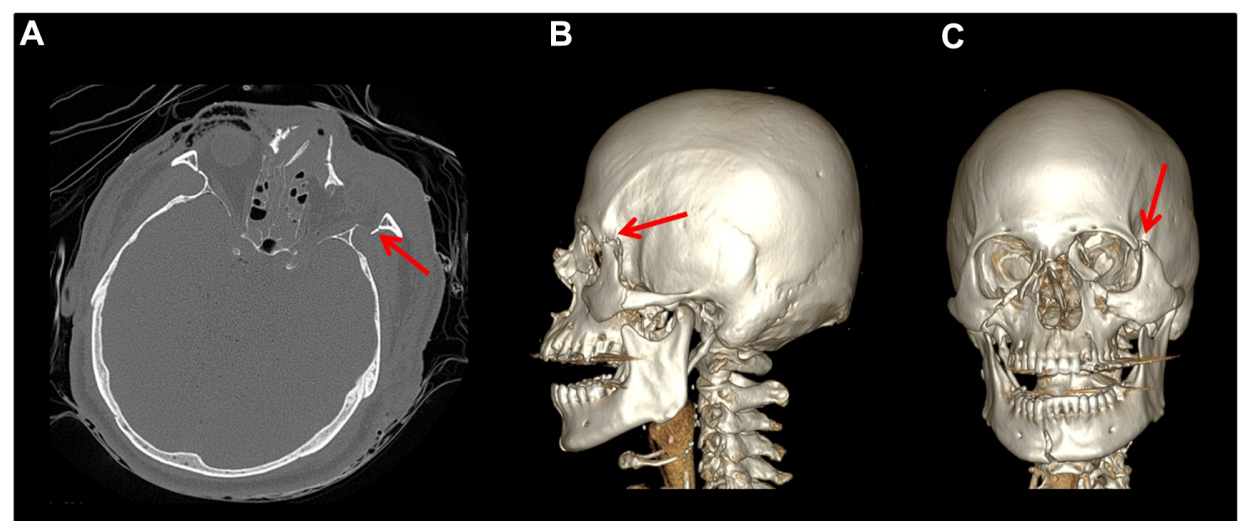

Figure 2 Visualization of bone lesions by PMCT.

Notes: Visualization of a fracture of the lateral wall of the left orbita (red arrow) by PMCT in $(\mathbf{A})$ a $2 \mathrm{D}$ axial reconstruction, (B) a lateral view from a 3D volume rendering reconstruction, and $(\mathbf{C})$ a slightly oblique frontal view from a 3D volume rendering reconstruction.

Abbreviation: PMCT, post-mortem computed tomography. 
PMCT clearly depicts calcifications of the coronary arteries (Figure 3). However, it does not allow the investigator to draw any conclusions regarding patency of the vessel's lumen or associated injury to the myocardium. As no blood flow is evident on PMCT, possible stenoses or occlusions cannot be assessed, although some correlation is possible via calculation of the calcium score. ${ }^{14}$

Given these considerations, the indications of PMCT in forensic medicine are especially focused on traumatic events, such as blunt violence, falls from heights, traffic accidents, badly damaged bodies (eg, due to train or airplane accidents), gunshot incidents, and cases in which foreign bodies must be sought (after the implantation of medical material or for investigating carbonized or putrefied corpses). PMCT is also an important tool in cases of infant deaths ${ }^{15,16}$ as well as child and elderly abuse ${ }^{17-19}$ because it yields a good and rapid overview of the skeletal system. It can be useful for estimating age, ${ }^{20-22}$ especially for bodies that lack an identity. PMCT is one of the fastest methods for detecting the abnormal presence of air or gas, which can often be difficult to find during autopsy. Its high sensitivity to the presence of gas allows detection of even the smallest amounts of gas, including accumulations in anatomic cavities or soft tissues $^{23}$ as well as air embolism, although care must be taken to correctly interpret the origin of the gas (putrefaction gas versus exogenic gas). ${ }^{24}$

Since the first report of PMCT in $1983,{ }^{25}$ the number of such investigations has risen all over the world; $;^{926-31}$ some

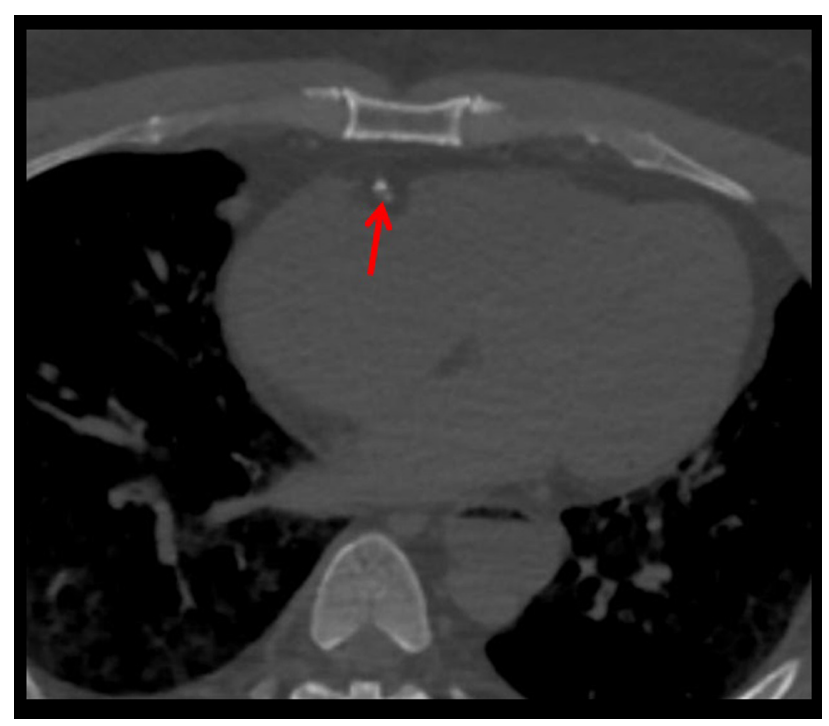

Figure 3 Visualization of a calcified plaque on the middle part of the right coronary artery (red arrow) in a 2D axial PMCT-based reconstruction.

Note: No information concerning the patency of the vessel's lumen can be obtained.

Abbreviation: PMCT, post-mortem computed tomography. forensic institutes are even starting to use PMCT in their daily routine. ${ }^{9,10,32-34}$ The frequency of examinations carried out in each facility and thus the width of indications depends on the availability of MDCT units. While some institutions have no access to MDCT, some use scanners available in the radiology departments of nearby hospitals, usually outside clinical hours. In the best-case scenario, institutions have their own MDCT scanners and can screen bodies prior to autopsy.

\section{PMCT-guided sampling}

MDCT enables the visualization of anatomical structures and abnormalities deep within the human body. In clinical practice, this feature allows minimally invasive extraction of histological samples and/or minimally invasive treatment procedures via accurate localization of the lesions/ structures.

The same idea can be translated to post-mortem imaging in order to obtain tissue samples from anatomic structures or lesions. ${ }^{35}$ This method can be particularly useful when autopsy is denied for religious ${ }^{36,37}$ or legal reasons. In clinical pathology, PMCT-guided sampling enables histological examination of any organ. A typical example is the sampling of lung tissue in cases in which post-mortem angiography using oily contrast agent is performed. Because injection of this contrast agent can mimic fatty embolism, it is essential to sample lung tissue before injection ${ }^{38,39}$ in order to obtain an accurate diagnosis and to determine the degree of fatty embolism.

Using the same approach, liquid samples can be obtained from the body via correct localization and puncture, a process that is of great interest in legal medicine. ${ }^{39} \mathrm{PMCT}$ also enables sterile puncturing for microbiological analyses. Small abscesses can be accessed via this method; they may be easily overlooked during autopsy or may be discovered only after contamination due to dissection. ${ }^{40}$ PMCT-guided puncture also enables toxicology of human fluids such as urine, bile, gastric contents, and other biological samples. ${ }^{39}$ This approach is particularly important when no autopsy can be performed or when post-mortem angiography is carried out, since samples must be collected prior to the injection of contrast medium in order to avoid contamination. ${ }^{41}$

Minimally invasive puncture also enables the controlled collection of gas samples, which is only possible to a limited extent during autopsy. As mentioned above, MDCT is an excellent tool for detecting even the smallest gas accumulations. ${ }^{23,24,42}$ Although highly sensitive for gases, MDCT offers no information about the provenance of gases within the body, and therefore it does not 
discriminate between ante-mortem gas due to air embolism or post-mortem accumulation due to incipient putrefaction. Frequently, the chemical analysis of gas via chromatography is necessary for a reliable diagnosis. Gas can be collected through minimally invasive punctures performed under PMCT guidance, transferred to specific sampling containers, and assayed for chemical composition ${ }^{43,44}$ (Figure 4). Determination of the exact composition of gas accumulations enables the accurate diagnosis of ante-mortem air embolism, decompression trauma in diving incidents, and intoxication with poisonous gases. ${ }^{45}$

\section{PMCT-angiography}

As mentioned above, PMCT is subject to important limitations in terms of the visualization of soft tissue, parenchyma, and vasculature. In clinical practice, contrast agent is injected into the patient via venous access and transported by the blood flow to various organs. This strategy allows evaluation of the vessel lumen and yields different contrast for different tissues, allowing the visualization of abnormalities. In accordance with this model, the idea of contrast-medium administration has been translated to post-mortem imaging. ${ }^{46}$ However, since there is no active blood flow in the vascular system of a corpse, the vessels are often nearly empty and collapsed. Additionally, vessels exhibit increased porosity post-mortem, rendering infeasible the simple injection of contrast medium used in the clinic. Large amounts of perfusion are needed in order to compensate for the lack of blood in the vascular system. ${ }^{46}$ Specific techniques and contrast agents are therefore required for PMCT-angiography.
In the past two decades, there has been great interest in developing post-mortem angiographic methods. In recent years, several authors have proposed various techniques, most of which still remain limited to experimental investigations or to specific scenarios. ${ }^{47,48}$ Targeted coronary angiography, which is applied regularly, was developed separately but nearly simultaneously by two centers in the United Kingdom. ${ }^{49,50}$ This technique fills the coronary arteries through cannulation of the aorta via the subclavian or neck arteries. The contrast agent is injected into the ascending aorta with a pressure high enough to perfuse the coronary arteries. Anterograde progression of the contrast agent is avoided by placing a balloon in the distal part of the ascending aorta. PMCT images are acquired during or after injection.

While this technique enables selective assessment of the coronary vessels, there remains a need to visualize the vascular system of the entire body. At the present time, multi-phase post-mortem computed tomography-angiography (MPMCTA) constitutes the most used and researched technique for post-mortem whole-body perfusion. ${ }^{38}$ In this minimally invasive procedure, the vascular system is perfused by injecting a mixture of paraffin oil and Angiofil ${ }^{\circledR}$, an oily contrast agent designed for post-mortem use. ${ }^{51}$ In contrast to aqueous liquids, oily liquids remain inside the lumen even in the heavily modified vessels of putrefied corpses. ${ }^{46,52}$ Access is obtained through careful dissection of the Scarpa triangle and cannulation of the femoral vessels. Reperfusion is achieved with a specific perfusion device designed for post-mortem angiography (Virtangio ${ }^{\circledR}$ ) that pumps the perfusion mixture into the arterial and venous systems. Grabherr et al proposed

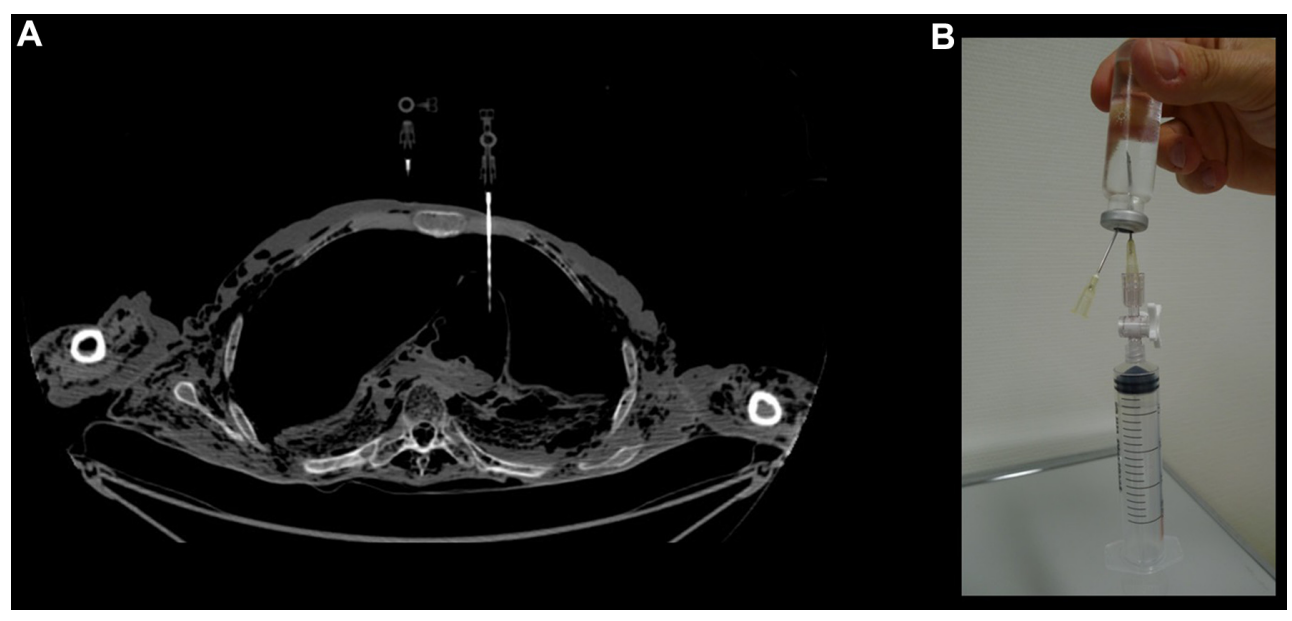

Figure 4 PMCT-guided sampling of gas.

Notes: Visualization of $(\mathbf{A})$ the sampling of intra-pericardial gas and $(\mathbf{B})$ injection of the collected gas into an ampoule for detailed analysis of a body with massive gas collections (a putrefied body). Note that the location of the needle tip and therefore the exact sample site is easily documented by performing PMCT with the needles in the sampling position.

Abbreviation: PMCT, post-mortem computed tomography. 
a standardized method for perfusion developed on a series of 45 cases. ${ }^{38}$ This method was validated in a 500-cases series, ${ }^{53}$ demonstrating its advantages and limitations (particularly in comparison with autopsy) as well as its validity for application in medico-legal cases (eg, no damage of the vascular system and no dislodging of ante-mortem blood clots). MPMCTA consists of four CT acquisitions: a native scan followed by three-phase injected angiography. By comparing images acquired in the native scan with those obtained during the arterial, venous, and dynamic phases, objective conclusions can be drawn and a clinical-like diagnosis can be made. A preliminary study of 50 forensic cases described the advantages and limitations of PMCT, MPMCTA, and autopsy. ${ }^{10}$ The sensitivity of PMCT with regard to organ findings was increased up to $\sim 81 \%$ after the injection of contrast medium, rendering it comparable with classical autopsy, which discovered $83 \%$ of all findings. ${ }^{10}$ The use of MPMCTA in in-hospital death was investigated by Wichmann et al, ${ }^{54}$ who reported similar results.

The advantages of PMCT angiography, particularly MPMCTA, are clearly derived from clinical practice. By visualizing even small-caliber vessels, it enables accurate localization of the sources of bleeding ${ }^{55}$ and reveals stenoses or vessel occlusions. ${ }^{56}$ The procedure can be particularly useful in cases of death after surgical procedures, as it can exclude bleeding or yield complete assessment of all vessels. ${ }^{40}$ It can also be suited to analysis of coronary arteries (Figure 5) and is thus an important tool for investigating the causes of natural cardiac death, ${ }^{57-59}$ guiding autopsy and histological sampling. Another major advantage of the technique is its clear visualization of the trajectories of stabbings and gunshots after contrast administration. ${ }^{60}$ MPMCTA-acquired images are particularly suitable for $2 \mathrm{D}$ and $3 \mathrm{D}$ reconstruction of these trajectories, which are very useful in court. Other PMCT-angiography-based methods can be applied for detecting vascular injuries due to stabbing or gunshots. ${ }^{61-64}$

\section{MRI}

In contrast to PMCT and conventional radiography, MRI involves no ionizing radiation; it is based on the principle of nuclear magnetic resonance. When a patient is placed in a magnetic field, the hydrogen protons in the body align with the field. A radiofrequency pulse is emitted from the scanner, exciting specific atomic nuclei and rotating the protons to a $180^{\circ}$ position. As the energy from the pulse decreases, the protons return to their initial state within the magnetic field and generate an MRI signal that is digitally transformed into images. The interval between arrival in the initial state and signal emission is called the relaxation time. Contrast between anatomical structures is possible due to the specific relaxation time of atoms within each tissue.

MRI offers high spatial resolution as well as excellent soft-tissue contrast, as it distinguishes muscles, fat, parenchyma, and neurological structures. It therefore complements PMCT, which has severe limitations due to a lack of discrimination in organ findings.

For this reason, MRI is of special significance for the diagnosis of natural death ${ }^{65-67}$ and for the assessment of traumatic soft-tissue injuries ${ }^{68-70}$ such as impact injuries after a traffic accident. In general, MRI is recommended in cases of blunt force, stab wounds, medical errors, and age estimation. ${ }^{20,71,72}$ It may be useful for detecting foreign bodies, ${ }^{69}$ but

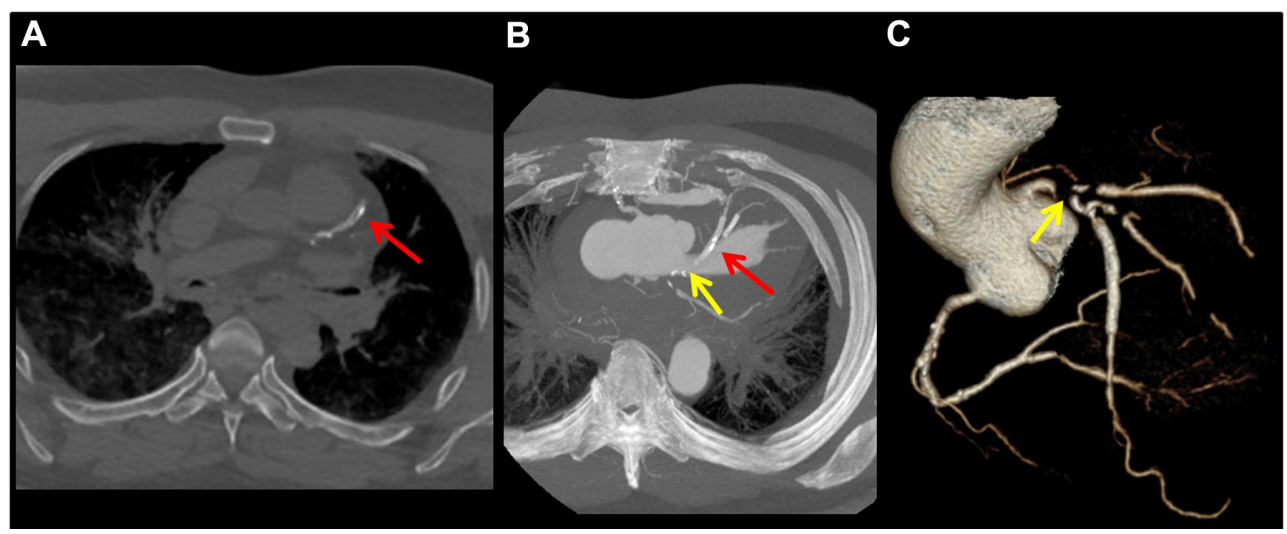

Figure 5 Images obtained from the arterial phase of MPMCTA in a case of sudden death of a person known to have a long history of coronaropathy and a coronary stent. Notes: Visualization of an intra-stent calcification (red arrow) on the left anterior descending artery in (A) a 2D axial reconstruction and (B) an axial maximum-intensity projection reconstruction. Also note the visualization of several filling defects of the lumen on the trajectory of the left anterior descending artery (yellow arrow) in (B) an axial maximum-intensity projection reconstruction and $(\mathbf{C})$ a 3D volume rendering reconstruction of the coronary arteries. Filling defects that are stable during phases of MPMCTA indicate the presence of sub-occlusive vascular stenosis.

Abbreviation: MPMCTA, multi-phase post-mortem computed tomography-angiography. 
with certain restrictions concerning ferromagnetic materials that could interact with the strong magnetic field. However, similar to PMCT-angiography, MRI yields valuable data for identifying strongly altered bodies, although the tool of choice for this indication is PMCT.

Today, MRI is successfully used by several institutions for investigations of malformations that cause death in infants and neonates. ${ }^{73-75}$ In such cases, which often occur outside of a medico-legal context, parents often do not consent to autopsy of the child, and thus MRI is the best alternative for documenting the cause of death. In addition to the benefits described above, MRI is an essential tool for cases of child abuse, ${ }^{76,77}$ as it strongly contributes to the detection of injury to soft tissue or organs.

In legal medicine, MRI is important for the assessment of cardiac pathology, especially in cases of sudden death. The myocardium must be examined in order to achieve complete cardiac imaging; MRI is the most sensible imaging modality in this regard. MRI accurately detects infarcted or ischemic regions in the heart muscle as well as fibrotic myocardial lesions, enabling early diagnosis of heart arrest. Peracute infarcted regions were previously detected with the help of MRI, ${ }^{67}$ although these regions are not evident (macroscopically) during autopsy or (microscopically) during histology. However, further investigations are needed in order to validate the use of MRI in post-mortem cardiac assessment, especially in terms of the immunohistochemistry of MRIbased suspicion of ischemic cardiac disease. In this context, increasing emphasis is placed on research into post-mortem MRI of the heart. ${ }^{78,79}$

In clinical forensic medicine, MRI is excellent for injury assessment in victims of violence. ${ }^{80}$ The absence of ionizing radiation allows the examination of patients even without a clinical indication. Given its high diagnostic value for soft tissues, MRI is now particularly indicated for the examination of internal findings in survivors of strangulation (Figure 6). ${ }^{81,82}$

Although MRI is excellent for examining the interior of a corpse, it is not used widely in modern forensic imaging, mainly because MRI scanners are less available than MDCT devices. The acquisition, maintenance, and handling of an MRI unit are very expensive and time-consuming, so few centers of legal medicine have their own MRI equipment. The reading and reporting of MRI-acquired images are considerably more complex than those of PMCT images; hence, well-trained personnel with specific expertise are required. In comparison with PMCT, which can be performed in clinical radiology departments after routine work, MRI requires a longer period of acquisition and the costs associated with it are considerably higher.

\section{D surface scanning}

As mentioned above, not all forensic-imaging techniques originated from radiology. Three-dimensional surface scanning is a technique that was developed for the car industry; it is extensively used for forensic investigations in Switzerland
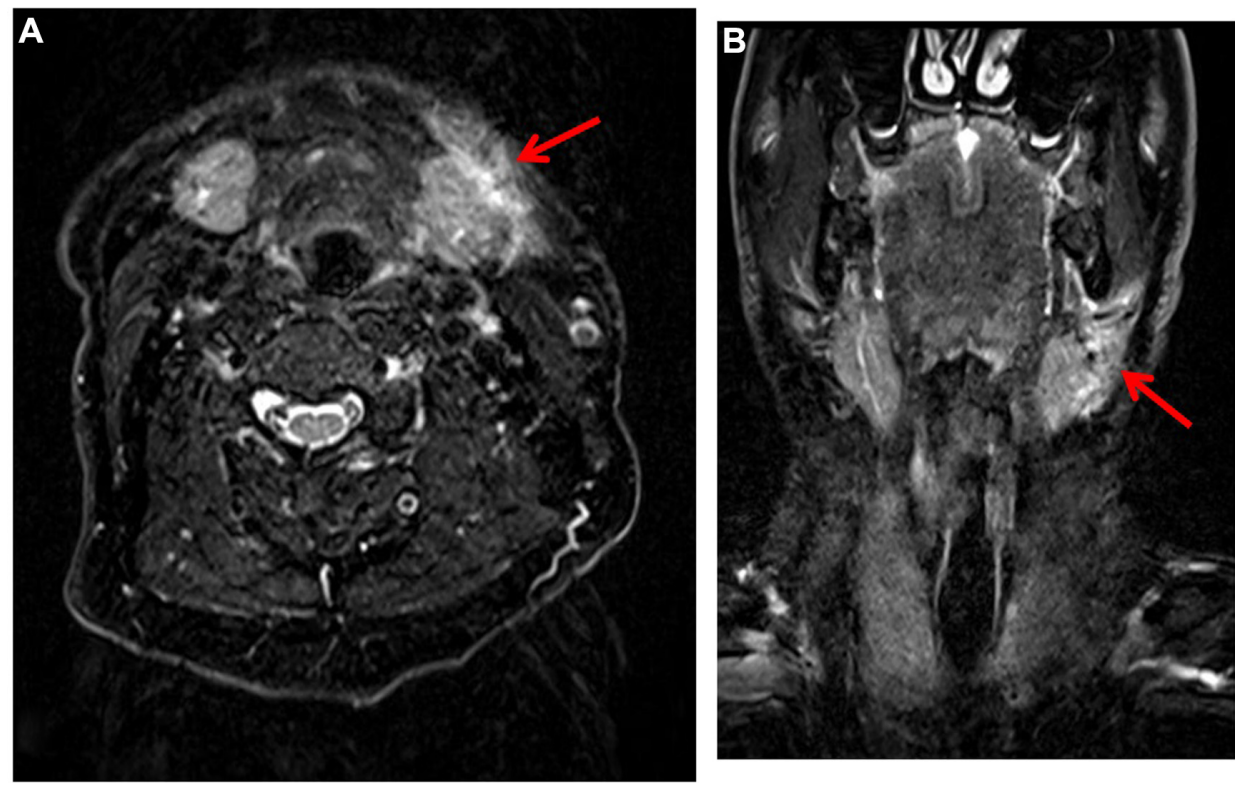

Figure $6 \mathrm{MRI}$ of a victim who survived strangulation ( I day after the aggression) in order to examine the profound structure of the neck.

Note: Visualization of a trauma-based soft-tissue edema (red arrow) in the left submandibular region on (A) a T2 axial view and (B) a T2 coronal view. Abbreviation: MRI, magnetic resonance imaging. 
by police and medico-legal institutions. Its main fields of application are the reconstruction of traffic accidents, ${ }^{83}$ the correlation of a lesion and the presumed injuring-causing instrument, ${ }^{84}$ and the comparison of bite marks with dental models of the supposed perpetrator. ${ }^{85}$

The surface scanners used in forensic medicine are called "fringe light scanners" and usually consist of a projector with one or two cameras. During the scanning phase, stripes of different size and distance pass behind the object like slides in a slide projector, creating the impression of movement due to the play of striped light over the surface of the object to be documented. The stripes are distorted during this process in accordance with the shape of the object, and this deformation is recorded with cameras. The device is connected to a computer, which is equipped with software for calculating 3D coordinates on the surface of the object over a very small distance. Calculation of these point clouds is based on the principle of triangulation. Powerful scanners calculate up to 16 million points on the surface of the object. Complex objects are completely digitized by repeatedly scanning at various angles and distances. Predefined reference marks fixed on or around the object enable merging of the individual scans into a single data set. At the end of the digitization process, the object is shown as a 3D model in digital form at high resolution. Various 3D modeling programs allow subsequent merging and overlaying of scanned objects for comparison of their structures (eg, comparison of a lesion on a body with the suspected injury-causing instrument; Figure 7). Today, fringe-light scanners have spatial resolutions of up to $0.017 \mathrm{~mm}$. Three-dimensional surface scanning can be combined with other imaging techniques such as photogrammetry, PMCT, and MRI, for example for reconstructing complex traffic accidents. ${ }^{83}$

According to its users, this technology is associated with numerous advantages. Three-dimensional surface scanning has been reported to be an objective, non-invasive method for $3 \mathrm{D}$ digitization of objects with high accuracy and resolution. It is relatively quick and easy to perform and allows data storage for later use or data exchange. ${ }^{83}$ However, 3D surface scanning also has limitations. Since the technique was originally developed for use in industry, certain applications in the software are not suitable for forensic purposes. For example, the scanner is optimized for flat surfaces; it was not designed for use on surfaces such as skin. ${ }^{86}$ Although repeatedly declared "easy to carry out", result quality strongly depends on the experience and skill of the user, particularly for event reconstruction and for comparing two objects. ${ }^{83}$ Thus, the "objectivity" of the method, which is often emphasized in publications, should be interpreted with caution. In our experience, the device is very sensitive to light and motion. The duration of the digitization of an object therefore varies widely and can increase significantly under inappropriate conditions. For example, the scanner has difficulty detecting a very dark or reflective surface, perhaps causing it to be

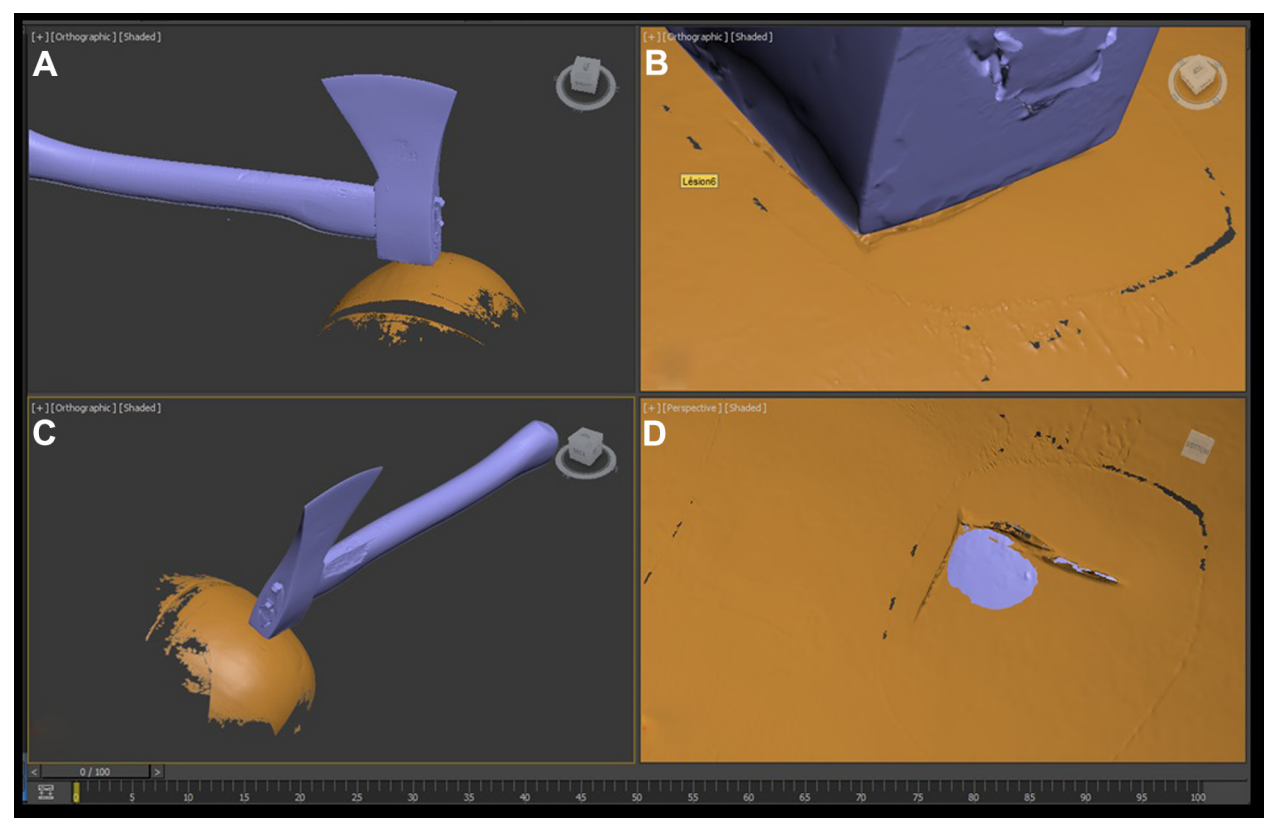

Figure 7 Visualization of the comparison of two 3D models obtained by surface scanning using a fringe-light scanner (Gom ATOS Compact Scan 5M, GOM mbH, Braunschweig, Germany).

Notes: To test the accuracy of the method, "lesions" on watermelons were produced with various instruments. Images show comparisons of the impact site on the melons' surface and an axe. (A-C) Views of a reconstructed impact between the axe and the watermelon. (D) Imprint of the back part of the axe on the surface of the watermelon. 
represented as a hole or a defect in the digital 3D model. This problem can often be resolved by applying special sprays, but these sprays are not applicable to all objects.

Despite these limitations, surface scanning and 3D modeling is an extremely impressive and useful tool for forensic imaging, with demonstrated advantages in several situations. When used properly, this technology may be key to solving complicated reconstructive questions. It undoubtedly will be improved and become widespread in the future.

\section{The role of forensic imaging in legal medicine}

Forensic imaging allows non-invasive or minimally invasive detection of several findings that may or may not be visible during classical autopsy. Digitization of bodies and objects is also possible through forensic imaging. However, a single procedure may not be sufficient for assessing a broader spectrum of findings, motivating the combination of methods for digitization of all findings. Imaging can yield information about findings for later confirmation during autopsy and guide the forensic pathologist to focus on a structure of interest, but it can also visualize lesions that would be impossible to discover and diagnose via standard autopsy alone (for example, detecting multiple small bleeding sources with PMCT-angiography).

Direct comparison of autopsy findings and imaging findings is not easy. Each technique has its advantages and disadvantages, ${ }^{9,10,84,87}$ and the sensitivity and specificity of imaging versus autopsy depend on the modality used and the case itself. ${ }^{10,88,89}$ Classic autopsy has its own strengths and weaknesses; in current practice, its value is enhanced by adding complementary techniques in order to establish a correct diagnosis. While some findings are directly evident in the autopsy room, many elements cannot be defined until further investigations are conducted, such as histological, microbiological, or toxicological examinations.

Similarly, one imaging modality or technique alone often does not lead to a precise diagnosis. Simple native CT may sometimes be sufficient to define all major findings necessary for identifying the cause of death, but not in most cases. For example, PMCT can be most accurate in a case of death due to a gunshot to the head; PMCT defines the entry and exit wounds, the presence of a projectile or fragments of it, the extent of cerebral lesions, and the trajectory of the bullet. It also predicts the vitality of the traumatic event by visualizing bronchoaspiration and gas embolism. However, regarding gunshot injury in the context of suicide, PMCT alone cannot exclude a pre-existing illness that perhaps motivated the suicide in the first place. In some cases, autopsy alone cannot address all issues, as it detects certain pathologies macroscopically without determining whether the pathology is benign or malignant in nature. Further investigations, particularly histology, are helpful in this regard. Toxicology assists in the determination of whether the person was under the influence of alcohol or drugs at the time of death.

Examination accuracy and the need for further investigative techniques always depend on the forensic question posed in each case. For each specific question, one or several methods can be used based on their availability. It is up to the forensic pathologist to choose the most accurate method for each case and to consider the advantages and disadvantages of each modality. The pathologist must establish an equilibrium between exam quality and the need for complementary analyses. Currently, the pathologist achieves the state of the art by selecting and combining "new" and "old" methods in order to optimize the investigation for each case. However, the choice of method(s) not only depends on the pathologist, but also on the availability of devices, personnel, and funds.

As described in this review, a variety of techniques for forensic imaging are currently available. Rigorous scientific research has demonstrated that depending on the medicolegal question, forensic-imaging techniques can be superior to classical autopsy and should therefore be applied, if possible in combination with other classic or newer methods. Although modern research relentlessly introduces new techniques, we believe that in order to increase the impact of forensic imaging, more forensic pathologists should be trained and forensic-imaging techniques should be made more readily available. Training forensic pathologists to apply and understand the technologies discussed here allows them to implement these methods in their daily casework and motivates them to create networks to increase the availability of these techniques. Forensic and legal medicine must be kept up to date because, depending on the questions that must be solved, classic autopsy alone can no longer be considered the gold standard.

\section{Acknowledgments}

Aurelian Costin Minoiu receives research support from Sectoral Operational Programme Human Resources Development, which is financed from the European Social Fund and by the Romanian Government under contract POSDRU/159/1.5/S/137390.

\section{Disclosure}

The authors report no conflicts of interest in this work. 


\section{References}

1. Thomas AMK, Banerjee K. The History of Radiology. Oxford: Oxford University Press; 2013.

2. Meadowcroft WH. The ABC of the X-Rays. London: Simpkin, Marshall, Hamilton, Kent \& Co; 1896.

3. Blundell RH, Wilson GH. Trial of Buck Ruxton. London: William Hodge \& Company; 1950.

4. Thiemann HH, Nitz I, Schmeling A (2006). Radiographic atlas of the normal hand at an early age. Thieme, Stuttgart, New York, 2006.

5. Greulich WW, Pyle Si. Radiographic Atlas of Skeletal Development of the Hand and Wrist. Stanford, CA: Stanford University Press; 1959.

6. Hajalioghli P, Tarzamni MK, Arami S, Fouladi DF, Ghojazadeh M. The utility of ultrasonographic bone age determination in detecting growth disturbances; a comparative study with the conventional radiographic technique. Skeletal Radiol. 2015;44(9):1351-1356.

7. Borowska-Solonynko A, Solonynko B. The use of 3D computed tomography reconstruction in medico-legal testimony regarding injuries in living victims - Risks and benefits. J Forensic Legal Med. 2015;30: 9-13.

8. Le Blanc-Louvry, Thureau S, Duval C, et al. Post-mortem computed tomography compared to forensic autopsy findings: a French experience. Eur Radiol. 2013;23(7):1829-1835.

9. Roberts IS, Benamore RE, Benbow EW, et al. Postmortem imaging as an alternative to autopsy in the diagnosis of adult deaths: a validation study. Lancet. 2012;379(9811):136-142.

10. Chevallier C, Doenz F, Vaucher P, et al. Postmortem computed tomography angiography vs conventional autopsy: advantages and inconveniences of each method. Int J Legal Med. 2013;127(5):981-989.

11. Makhlouf F, Scolan V, Ferretti G, Stahl C, Paysant F. Gunshot fatalities: correlation between post-mortem multi-slice computed tomography and autopsy findings: a 30-months retrospective study. Leg Med (Tokyo). 2013;15(3):145-148.

12. Peschel O, Szeimies U, Vollmar C, Kirchhoff S. Postmortem 3-D reconstruction of skull gunshot injuries. Forensic Sci Int. 2013; 233(1-3):45-50.

13. Tartaglione T, Filograna L, Roiati S, Guglielmi G, Colosimo C, Bonomo L. Importance of 3D-CT imaging in single-bullet cranioencephalic gunshot wounds. Radiol Med. 2012;117(3):461-470.

14. Rusu MC, Cuzino D, Dermengiu D, et al. Coronary artery calcium scoring in postmortem specimens. Mehod report. Romanian Journal of Legal Medicine. 2009;17(4):271-276.

15. Arthurs OJ, Van Rijn RR, Taylor AM, Sebire NJ. Paediatric and perinatal postmortem imaging: the need for a subspecialty approach. Pediatr Radiol. 2015;45(4):483-490.

16. Arthurs OJ, Van Rijn RR, Sebire NJ. Current status of paediatric post-mortem imaging: an ESPR questionnaire-based survey. Pediatr Radiol. 2014;44(3):244-251.

17. Berdon WE, Feldman KW. A modest proposal: thoracic CT for rib fracture diagnosis in child abuse. Child Abuse Negl. 2012;36(2):200-201.

18. Sanchez TR, Lee JS, Coulter KP, Seibert JA, Stein-Wexler R. CT of the chest in suspected child abuse using submillisievert radiation dose. Pediatr Radiol. 2015;45(7):1072-1076.

19. Murphy K, Waa S, Jaffer H, Sauter A, Chan A. A literature review of findings in physical elder abuse. Can Assoc Radiol J. 2013;64(1):10-14.

20. Dedouit F, Saint-Martin P, Mokrane FZ, et al. Virtual anthropology: useful radiological tools for age assessment in clinical forensic medicine and thanatology. Radiol Med. 2015;120(9):874-886.

21. de Froidmont S, Grabherr S, Vaucher P, et al. Virtual anthropology: a comparison between the performance of conventional X-ray and MDCT in investigating the trabecular structure of long bones. Forensic Sci Int. 2013;225(1-3):53-59.

22. Dedouit F, Savall F, Mokrane FZ, et al. Virtual anthropology and forensic identification using multidetector CT. Br J Radiol. 2014;87(1036): 20130468.

23. Egger C, Bize P, Vaucher P, et al. Distribution of artifactual gas on post-mortem multidetector computed tomography (MDCT). Int J Legal Med. 2012;126(1):3-12.
24. Egger C, Vaucher P, Doenz F, Palmiere C, Mangin P, Grabherr S. Development and validation of a postmortem radiological alteration index: the RA-Index. Int J Legal Med. 2013:225(1-3):53-59.

25. Krantz P, Holtås S. Postmortem computed tomography in diving fatality. J Comput Assist Tomogr. 1983;7(1):132-134.

26. Dirnhofer R, Jackowski C, Vock P, Potter K, Thali MJ. VIRTOPSY: minimal invasive, imaging guided virtual autopsy. Radiographics. 2006; 26(5):1305-1333

27. Weustink AC, Hunink MG, van Dijke CF, Renken NS, Krestin GP, Oosterhuis JW. Minimally invasive autopsy: an alternative to conventional autopsy? Radiology. 2009;250(3):897-904.

28. Jeffery AJ. The role of computed tomography in adult post-mortem examinations: an overview. Diagnostic histopathology. 2010;16(12): 546-551.

29. Okuda T, Shiotani S, Sakamoto N, Kobayashi T. Background and current status of post-mortem imaging in Japan: short history of "Autopsy imaging (Ai)". Forensic Sci Int. 2013;225(1-3):3-8.

30. Donchin Y, Rivkind AI, Bar-Ziv J, Hiss J, Almong J, Drescher M. Utility of postmortem computed tomography in trauma victims. J Trauma. 1994;37(4):552-555.

31. Kasahara S, Makino Y, Hayakawa M, Yajima D, Ito H, Iwase H. Diagnosable and non-diagnosable causes of death by postmortem computed tomography: a review of 339 forensic cases. Leg Med (Tokyo). 2012;14(5):239-245.

32. O'Donnell C. An image of sudden death: utility of routine postmortem computed tomography scanning in medico-legal autopsy practice. Diagnostic histopathology. 2010;16(12):552-555.

33. Poulsen K, Simonsen J. Computed tomography as routine in connection with medico-legal autopsies. Forensic Sci Int. 2007;171(2-3): 190-197.

34. Roberts IS, Traill ZC. Minimally invasive autopsy employing post-mortem CT and targeted coronary angiography: evaluation of its application to a routine Coronial service. Histopathology. 2014;64(2):211-217.

35. Aghayev E, Thali MJ, Sonnenschein M, Jackowski C, Dirnhofer R, Vock P. Post-mortem tissue sampling using computed tomography guidance. Forensic Sci Int. 2007;166(2-3):199-203.

36. Kang X, Cos T, Guizani M, Cannie MM, Segers V, Jani JC. Parental acceptance of minimally invasive fetal and neonatal autopsy compared with conventional autopsy. Prenat Diagn. 2014;34(11):1106-1110.

37. Mohammed M, Kharoshah MA. Autopsy in Islam and current practice in Arab Muslim countries. J Forensic Leg Med. 2014;23:80-83.

38. Grabherr S, Doenz F, Steger B, et al. Multi-phase post-mortem CTangiography Development of a standardized protocol. Int J Legal Med. 2011;125(6):791-802.

39. Schneider B, Chevallier C, Dominguez A, et al. The Forensic Radiographer: A New Member in the Medico-legal Team. Am J Forensic Med Pathol. 2012;33(1):30-36.

40. Zerlauth JB, Doenz F, Dominguez A, et al. Surgical interventions with fatal outcome: Utility of multi-phase postmortem CT angiography. Forensic Sci Int. 2013:225(1-3):32-41.

41. Palmiere C, Grabherr S, Augsburger M. Postmortem computed tomography angiography, contrast medium administration and toxicological analyses in urine. Leg Med (Tokyo). 2015;17(3):157-162.

42. Gebhart FT, Brogdon BG, Zech WD, Thali MJ, Germerott T. Gas at postmortem computed tomography--an evaluation of 73 non-putrefied trauma and non-trauma cases. Forensic Sci Int. 2012;222(1-3):162-169.

43. Varlet V, Smith F, de Froidmont S, et al. Innovative method for carbon dioxide determination in human postmortem cardiac gas samples using headspace-gas chromatography-mass spectrometry and stable labeled isotope as internal standard. Anal Chim Acta. 2013;784: 42-46.

44. Varlet V, Bruguier C, Grabherr S, Augsburger M, Mangin P, Uldin T. Gas analysis of exhumed cadavers buried for 30 years: a case report about long time alteration. Int J Legal Med. 2014;128(4):719-724.

45. Varlet V, Smith F, Giuliani N, et al. When gas analysis assists with postmortem imaging to diagnose causes of death. Forensic Sci Int. 2015;251:1-10. 
46. Grabherr S, Grimm J, Baumann P, Mangin P. Application of contrast media in post-mortem imaging (CT and MRI). Radiol Med. 2015;120(9):824-834.

47. Saunders SL, Morgan B, Raj V, Rutty GN. Post-mortem computed tomography angiography: past, present and future. Forensic Sci Med Pathol. 2011;7(3):271-277.

48. Grabherr S, Grimm J, Dominguez A, Vanhaebost J, Mangin P. Advances in post-mortem CT-angiography. Br J Radiol. 2014; 87(1036):20130488.

49. Saunders SL, Morgan B, Raj V, Robinson CE, Rutty GN. Targeted post-mortem computed tomography cardiac angiography: proof of concept. Int J Legal Med. 2011;125(4):609-616.

50. Roberts IS, Benamore RE, Peebles C, Roobottom C, Traill ZC. Diagnosis of coronary artery disease using minimally invasive autopsy: evaluation of a novel method of post-mortem coronary CT angiography. Clin Radiol. 2011;66(7):645-650.

51. Grabherr S, Hess A, Karolczak M, et al. Angiofil-Mediated Visualization of the Vascular System by Microcomputed Tomography: A Feasibility Study. Microsc Res Tech. 2008;71(7):551-556.

52. Grabherr S, Djonov V, Friess A, et al. Postmortem angiography after vascular perfusion with diesel oil and a lipophilic contrast agent. AJR Am J Roentgenol. 2006;187(5):W515-W523.

53. Grimm J, Heinemann A, Guglielmi G, et al. Challenging the Role of Autopsy - Results of a Multicenter Study to Validate Multi-Phase Postmortem CT-Angiography (MPMCTA). Proceedings of the 67th Annual Scientific Meeting of the American Academy of Forensic Sciences; February 2015; Orlando.

54. Wichmann D, Heinemann A, Weinberg C, et al. Virtual autopsy with multiphase postmortem computed tomographic angiography versus traditional medical autopsy to investigate unexpected deaths of hospitalized patients: a cohort study. Ann Intern Med. 2014;15;160(8):534-541.

55. Palmiere C, Binaghi S, Doenz F, et al. Detection of hemorrhage source: the diagnostic value of post-mortem CT-angiography. Forensic Sci Int. 2012;222(1-3):33-39.

56. Michaud K, Grabherr S, Doenz F, Mangin P. Evaluation of postmortem MDCT and MDCT-angiography for the investigation of sudden cardiac death related to atherosclerotic coronary artery disease. Int J Cardiovasc Imaging. 2012;28(7):1807-1822.

57. Inokuchi G, Yajima D, Hayakawa M, et al. The utility of postmortem computed tomography selective coronary angiography in parallel with autopsy. Forensic Sci Med Pathol. 2013;9(4):506-514.

58. Morgan B, Biggs MJ, Barber J, et al. Accuracy of targeted post-mortem computed tomography coronary angiography compared to assessment of serial histological sections. Int J Legal Med. 2013;127(4):809-817.

59. Michaud K, Grabherr S, Jackowski C, Bollmann MD, Doenz F, Mangin P. Postmortem imaging of sudden cardiac death. Int $J$ Legal Med. 2013;128(1):127-137.

60. Grabherr S, Grimm J. Multiphase Post-Mortem Ct-angiography (MPMCTA): A new method for investigation Violent Death. In: Vogel B, Vogel H. Forensics, Radiology, Society X-Rays: Tool and Document. Hamburg: Kovač Verlag; 2014:156-163.

61. Ruder TD, Ross S, Preiss U, Thali MJ. Minimally invasive post-mortem CT-angiography in a case involving a gunshot wound. Leg Med (Tokyo). 2010;12(3):154-156.

62. Kominato Y, Tajima Y, Fujikura T, et al. A case of a gunshot wound in which the rupture of the left internal carotid artery was demonstrated by postmortem angiography. Leg Med (Tokyo). 2007;9(1):22-24.

63. Savall F, Dedouit F, Mokrane FZ, Rougé D, Saint-Martin P, Telmon N. An unusual homicidal stab wound of the cervical spinal cord: A single case examined by post-mortem computed tomography angiography (PMCTA). Forensic Sci Int. 2015;254:e18-e21.

64. Ruder TD, Ketterer T, Preiss U, et al. Suicidal knife wound to the heart: challenges in reconstructing wound channels with post mortem $\mathrm{CT}$ and CT-angiography. Leg Med (Tokyo). 2011;13(2):91-94.

65. Ruder TD, Ebert LC, Khattab AA, Rieben R, Thali MJ, Kamat P. Edema is a sign of early acute myocardial infarction on post-mortem magnetic resonance imaging. Forensic Sci Med Pathol. 2013;9(4):501-505.
66. Puranik R, Gray B, Lackey H, et al. Comparison of conventional autopsy and magnetic resonance imaging in determining the cause of sudden death in the young. J Cardiovasc Magn Reson. 2014;16:44.

67. Jackowski C, Schwendener N, Grabherr S, Persson A. Post-mortem cardiac 3-T magnetic resonance imaging: visualization of sudden cardiac death? J Am Coll Cardiol. 2013;62(7):617-629.

68. Ross S, Ebner L, Flach P, et al. Postmortem whole-body MRI in traumatic causes of death. AJR Am J Roentgenol. 2012;199(6):1186-1192.

69. Ruder TD, Thali MJ, Hatch GM. Essentials of forensic post-mortem MR imaging in adults. Br J Radiol. 2014;87(1036):20130567.

70. Yen K, Vock P, Tiefenthaler B, et al. Virtopsy: forensic traumatology of the subcutaneous fatty tissue; multislice computed tomography (MSCT) and magnetic resonance imaging (MRI) as diagnostic tool. $J$ Forensic Sci. 2004;49(4):799-806.

71. Baumann P, Widek T, Merkens H, Boldt J, et al. Dental age estimation of living persons: Comparison of MRI with OPG. Forensic Sci Int. 2015;253:76-80.

72. Schmidt S, Vieth V, Timme M, Dvorak J, Schmeling A. Examination of ossification of the distal radial epiphysis using magnetic resonance imaging. New insights for age estimation in young footballers in FIFA tournaments. Sci Justice. 2015;55(2):139-144.

73. Jawad N, Sebire N, Wade A, Taylor A, Chitty L, Arthurs O. Bodyweight limits of fetal Post Mortem MRI at 1.5T. Ultrasound Obstet Gynecol. Epub 2015 Jul 16.

74. Arthurs O, Thayyil S, Pauliah S, et al. Magnetic Resonance Imaging Autopsy Study (MaRIAS) Collaborative Group. Diagnostic accuracy and limitations of post-mortem MRI for neurological abnormalities in fetuses and children. Clin Radiol. 2015;70(8):872-880.

75. Addison S, Arthurs O, Thayyil S. Post-mortem MRI as an alternative to non-forensic autopsy in foetuses and children: from research into clinical practice. Br J Radiol. 2014;87(1036):20130621.

76. Pluchinotta FR, Porayette P, Zaidi AH, et al. Postmortem imaging in congenital heart disease: preliminary experience. Acta Radiol. 2015;56(10):1264-1272.

77. Buttram S, Garcia-Filion P, Miller J, et al. Computed tomography vs magnetic resonance imaging for identifying acute lesions in pediatric traumatic brain injury. Hosp Pediatr. 2015;5(2):79-84.

78. Taylor A, Arthurs O, Sebire N. Postmortem cardiac imaging in fetuses and children. Pediatr Radiol. 2015;45(4):549-555.

79. Zech WD, Schwendener N, Persson A, Warntjes MJ, Jackowski C. Postmortem MR quantification of the heart for characterization and differentiation of ischaemic myocardial lesions. Eur Radiol. 2015; 25(7):2067-2073.

80. Glemser PA, Krauskopf A, Simons D, Yen K. Klinisch-forensische Bildgebung: Erfassung und Dokumentationen innere Verletzungsbefunde bei lebenden Gewaltopfern [Clinical forensic imaging: detection and documentation of inner lesions in living crime victims]. Rechtsmedizin. 2015;25:67-79. German.

81. Christe A, Oesterhelweg L, Ross S, et al. Can MRI of the neck compete with clinical findings in assessing danger to life for survivors of manual strangulation? A statistical analysis. Leg Med (Tokyo). 2010;12(5):228-232.

82. Yen K, Vock P, Christe A, et al. Clinical forensic radiology in strangulation victims: forensic expertise based on magnetic resonance imaging (MRI) findings. Int J Legal Med. 2007;121(2):115-123.

83. Buck U, Naether S, Braun M. Application of 3D documentation and geometric reconstruction methods in traffic accident analysis: With high resolution surface scanning, radiological MSCT/MRI scanning and real data based animation. Forensic Sci Int. 2007;170(1): 20-28.

84. Thali M, Braun M, Brueschweiler W, Dirnhofer R. "Morphological imprint": determination of the injury-causing weapon from the wound morphology using forensic 3D/CAD-supported photogrammetry. Forensic Sci Int. 2003;132(3):177-181.

85. Naether S, Buck U, Campana L, Breitbeck R, Thali M. The examination and identification of bite marks in foods using 3D scanning and 3D comparison methods. Int J Legal Med. 2012;126(1):89-95. 
86. Schweitzer W, Röhrich E, Schaepman M, Thali MJ, Ebert L. Aspects of 3D surface scanner performance for post-mortem skin documentation in forensic medicine using rigid benchmark objects. J Forensic Rad Imaging. 2013;1(4):167-175.

87. Grabherr S, Baumann P, Fahrni S, Mangin P, Grimm J. Virtuelle vs reale forensische bildgebende Verfahren-Einsatzgebiete, Vorteile und Limits [Virtual vs real forensic imaging. Methods, application, strengths and weaknesses]. Rechtsmedizin. 2015(5):493-509. German.
88. Mokrane FZ, Savall F, Blanc A, et al. The usefulness of post-mortem CT angiography in injuries caused by falling from considerable heights: three fatal cases. Diagn Interv Imaging. 2014;95(11): 1085-1090.

89. Thayyil S, Sebire NJ, Chitty LS, et al. MARIAS collaborative group Post-mortem MRI versus conventional autopsy in fetuses and children: a prospective validation study. Lancet. 2013;382(9888):223-233.

\section{Publish your work in this journal}

Research and Reports in Forensic Medical Science is an international, peer-reviewed, open access journal publishing original research, reports, reviews and commentaries on all areas of forensic medical science. The manuscript management system is completely online and includes a very quick and fair peer-review system. Visit http://www.dovepress.com/ testimonials.php to read real quotes from published authors. 